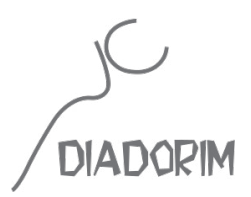

\title{
ANÁLISE ENTONACIONAL DA LEITURA DE TELEJORNAIS CHILENOS E ESPANHÓIS COM BASE NA TEORIA DA LÍNGUA EM ATO
}

José Ricardo Dordron de Pinho ${ }^{1}$

DOI: http://doi.org/10.35520/diadorim.2015.v17n2a4070

\section{RESUMO}

Este trabalho tem por objetivo realizar uma descrição entonacional do fonoestilo leitura de notícias de telejornais em língua espanhola por apresentadores homens e mulheres das variedades chilena e espanhola. Para tanto, aplicamos aos dados uma análise das funções informativas, segundo a Teoria da Língua em Ato. De acordo com a mesma, em nosso corpus, poderíamos encontrar 6 de suas unidades de informação; no entanto, apenas 4 foram efetivamente observadas: tópico, comentário, apêndice de tópico e apêndice de comentário. As duas últimas são bastante raras. Ainda que o comentário seja um elemento obrigatório e o tópico não, para a Teoria da Língua em Ato, a frequência de ocorrência dessa segunda função informativa é bastante alta em nossos enunciados, o que indica um alto grau de topicalização que caracterizaria o fonoestilo em questão. Para o tópico, foram identificados os mesmos 3 perfis melódicos descritos para o italiano, com foco à direita. Para o comentário, encontramos movimentos de $\mathrm{F}_{0}$ que caracterizam um comentário ligado não final, um comentário ligado não final mas final de sequência e um comentário em final de leitura. Os correlatos morfossintáticos do tópico tendem a ser substantivos e os do comentário, verbos.

PALAVRAS-CHAVE: Entoação; prosódia; fonoestilo telejornal; espanhol no Chile e na Espanha; Teoria da Língua em Ato.

\section{RESUMEN}

Este trabajo tiene por objetivo realizar una descripción entonacional del fonoestilo lectura de noticias de noticieros en lengua española por presentadores hombres y mujeres de las variedades chilena y española. Para tanto, aplicamos a los datos un análisis de las funciones informativas, según la Teoría de la Lengua en Acto. De acuerdo con la misma, en nuestro corpus, podríamos encontrar 6 de sus unidades de información; sin embargo, solamente 4 fueron efectivamente

1 Colégio Pedro II; ricardodordron@bol.com.br.

Diadorim, Rio de Janeiro, Revista 17 volume 2, p. 67-89, Dezembro 2015. 
observadas: tópico, comentario, apéndice de tópico y apéndice de comentario. Las dos últimas son bastante raras. Aunque el comentario sea un elemento obligatorio y el tópico no, para la Teoría de la Lengua en Acto, la frecuencia de ocurrencia de esta segunda función informativa es bastante alta en nuestros enunciados, lo que indica un alto grado de topicalización que caracterizaría el fonoestilo en cuestión. Para el tópico, fueron identificados los mismos 3 perfiles melódicos descritos para el italiano, con foco a la derecha. Para el comentario, encontramos movimientos de $\mathrm{F}_{0}$ que caracterizan un comentario ligado no final, un comentario ligado no final pero final de secuencia y un comentario en final de lectura. Los correlatos morfosintácticos del tópico tienden a ser sustantivos y los del comentario, verbos.

PALABRAS CLAVE: Entonación; prosodia; fonoestilo noticiero; español en Chile y en España; Teoría de la Lengua en Acto.

\section{INTRODUÇÃO}

A entoação é um elemento de fundamental importância para a comunicação em certos sistemas linguísticos, uma vez que permite ao ouvinte identificar intenções linguísticas do falante; por exemplo, se o que diz é uma asserção ou uma interrogação. Além dos elementos linguísticos, a entoação também é um elemento-chave para a identificação ou o reconhecimento de funções expressivas, informativas, marcas de indexações sociais ou traços individuais idioletais dos falantes.

Com o objetivo de contribuir para um maior conhecimento dos aspectos entonacionais da língua espanhola, este trabalho pretende descrever, do ponto de vista entonacional, a leitura de notícias por apresentadores de telejornais em duas variedades do espanhol: a chilena e a espanhola. Parece-nos que o fonoestilo em questão (leitura de telejornais) apresenta certas especificidades que procuraremos descrever; porém, também cremos que há diferenças do ponto de vista diatópico. Ainda trabalhamos com os sexos separadamente, com a intenção de verificar se há diferenças quanto a esse item; no entanto, acreditamos que não haja diferenças significativas e que os dados possam ser unificados (quanto a esse aspecto).

Para realizar a descrição proposta, apresentamos aspectos teóricos sobre a Teoria da Língua em Ato (breve apresentação das funções informativas da prosódia a partir da referida teoria), a metodologia utilizada (incluindo a obtenção, a seleção e a descrição do corpus) e a análise propriamente dita.

\section{A estrutura informativa e a Teoria da Língua em Ato}

Ao produzir um enunciado, o falante elabora o seu discurso de modo a encontrar as necessidades particulares do receptor pretendido (PRINCE apud LAMBRECHT, 1994), ou seja, adapta a forma da sua produção refletindo suas hipóteses sobre as suposições, crenças e estratégias do receptor. A expressão "estrutura informativa" se refere à forma das produções em relação aos estados mentais assumidos por falantes e ouvintes; tem mais a ver com como o conteúdo é transmitido do que com o conteúdo propriamente dito (CHAFE apud LAMBRECHT, 1994). Dessa forma, o estudo da estrutura informativa não se relaciona ao conteúdo lexical e proposicional em abstrato, mas ao modo como o conteúdo é transmitido. 
De acordo com Lambrecht (1994, p.1), ainda há confusão sobre a natureza da "estrutura da informação" e sobre seu status no sistema gramatical. As dificuldades do seu estudo se devem, em parte, ao fato de a análise gramatical associar-se à relação entre forma linguística e estados mentais dos falantes e dos ouvintes e também por os linguistas da área precisarem lidar com aspectos formais e comunicativos da linguagem. As dificuldades encontradas na análise do componente da estrutura informativa se refletem em problemas terminológicos, com o uso de nomes diferentes de acordo com correntes diferentes. De qualquer maneira, o uso da expressão "estrutura informativa" se deve à ênfase dada nas implicações estruturais da análise pragmática do discurso.

Lambrecht (1994, p.5) define a estrutura informativa como um componente da gramática da sentença, em que proposições como representações conceptuais são emparelhadas com estruturas léxico-gramaticais de acordo com os estados mentais dos interlocutores que usam e interpretam estas estruturas como unidades de informação em dados contextos discursivos. $\mathrm{O}$ domínio formal da estrutura informativa, portanto, será a sentença; assim, a estrutura informativa pertence à gramática da sentença, não se relacionando à organização do discurso, mas à organização da sentença dentro do discurso. A forma gramatical das sentenças é motivada pelas necessidades da estrutura informativa.

É importante mencionar que a sintaxe não é o único nível formal em que a estrutura informativa é codificada. O que a sintaxe não codifica é codificado pela prosódia e o que não é codificado pela prosódia pode ser expresso pela morfologia ou pelo léxico. Existem distinções pragmáticas marcadas apenas fonologicamente, que não envolvem estruturas sintáticas alternativas; é o caso do foco prosódico.

O foco corresponde a um núcleo prosódico, ou seja, à proeminência mais relevante (de acordo com Arantes, Lima e Barbosa (2012, p.4), a proeminência prosódica não direciona a atenção para uma palavra em particular dentro do enunciado, mas realiza a interação entre as expectativas semânticas e pragmáticas). Segundo Lambrecht (1994, p.27), o acento de foco pode ser visto não como uma característica prosódica, mas como uma característica sintática abstrata (sem realização sintática).

Para Lambrecht (1994, p.6), a estrutura informativa se manifesta formalmente em aspectos da prosódia (especialmente marcadores gramaticais), na forma de constituintes sintáticos (particularmente nominais), na posição e ordenação de tais constituintes na sentença, na forma de construções gramaticais complexas e em certas escolhas entre itens lexicais que se relacionam. Neste trabalho, interessa-nos, em especial, estudar a estrutura informacional da fala a partir da sua segmentação prosódica; para tanto, levamos em consideração a Teoria da Língua em Ato.

Para a Teoria da Língua em Ato (TLA), o ato de fala é a atividade fundamental da comunicação e, na análise da fala, de acordo com Cresti (2000), as primeiras unidades linguísticas que podem ser obtidas de maneira natural são as falas ou turnos dialógicos de um falante, de silêncio a silêncio. A Teoria da Língua em Ato pesquisa a atividade que sustenta o falar e, mais precisamente, os atos comunicativos de que ele é composto e as expressões resultantes, chamadas de enunciados (correspondente linguístico de um ato, que é escolhido como unidade linguística de referência).

A Teoria da Língua em Ato é sintetizada em Mittman (2012), na qual se observa que a definição apresentada para o termo "enunciado", no parágrafo anterior, se baseia na hipótese de que é Diadorim, Rio de Janeiro, Revista 17 volume 2, p. 67-89, Dezembro 2015. 
possível definir a equivalência entre unidades do domínio do agir humano (atos) e unidades linguísticas (enunciados). Desse modo, é necessário considerar o enunciado como a unidade linguística básica da fala, uma vez que corresponde ao componente linguístico de um ato de fala.

Como visto, considera-se possível uma equivalência entre unidades do domínio das ações humanas, os atos, e unidades linguísticas, os enunciados. No primeiro domínio, encontram-se os diversos atos que podem ser realizados, como pedidos, saudações e ordens; já no domínio da língua, os referidos atos são expressos através de uma força ilocucionária, que se codifica na forma de uma expressão linguística que pode ser interpretada do ponto de vista pragmático. Em síntese, podemos afirmar que o enunciado corresponde à unidade pragmaticamente autônoma do contínuo da fala.

O que justifica a equivalência entre unidades de ação e unidades linguísticas, segundo a TLA, é o fato de o ato de fala apresentar três atos simultâneos: o locucionário, o ilocucionário e o perlocucionário. O ato locucionário é o ato de dizer, a produção linguística, a ação de falar em si; o ato ilocucionário é o ato de fazer com o dizer, corresponde à ação realizada através da fala (como a de prometer, ordenar...); e o ato perlocucionário é a produção de um efeito (resposta acional) sobre o interlocutor. Segundo a TLA, o enunciado corresponde ao ato locucionário, ou seja, à parte linguística do ato de fala, e ele se encontra imbuído de uma força ilocucionária.

Para a TLA, o critério formal para identificar enunciados no contínuo da fala é a avaliação de características entonacionais, a ser realizada com base na percepção de um falante competente. O que justifica tal afirmação é o fato de a ilocução de um enunciado ser veiculada por meio da entoação. Para a TLA, é a prosódia que realiza a interface entre unidades pragmáticas (atos) e unidades linguísticas (enunciados). De acordo com Raso (2012), tal teoria entende que "há níveis hierárquicos definidos na expressão comunicativa da fala que devem ser considerados; a sua não consideração levaria à impossibilidade de se conseguir analisar os textos falados”. Uma análise desse tipo pressupõe a necessidade de que se individualize a unidade ilocucionária e que, dentro dessa unidade, se individualize a sua estrutura informacional.

Cresti (2000) assinala que as funções linguísticas da entoação são as seguintes: (a) indica o tipo de ilocução realizada no ato de fala, (b) delimita os enunciados no contínuo fônico, (c) segmenta o enunciado em unidades menores (unidades tonais) e (d) assinala o tipo informacional de cada unidade dentro do enunciado.

A segmentação do contínuo fônico em enunciados é feita a partir de variações prosódicas que são perceptivelmente relevantes e o dividem em unidades prosódicas discretas. Essas variações podem transmitir um valor conclusivo (terminal) ou não conclusivo (não terminal); no primeiro caso, em que se observa uma quebra prosódica terminal, é importante mencionar que dita quebra prosódica não deve ser confundida com uma pausa, que é um silêncio realizado pelo falante. E são as quebras não terminais que delimitam as unidades tonais internas ao enunciado.

A partir da segmentação prosódica da fala, obtém-se a base para a estruturação informacional, pois as unidades do padrão prosódico correspondem a unidades do padrão informacional. A TLA entende a unidade de informação como um conjunto de palavras (ou mesmo apenas uma) que é assinalada por uma unidade tonal e identificada pela execução de uma específica função informativa. Cada unidade de informação possui apenas uma avaliação modal pelo falante. Mittman (2012) define o padrão informacional como "um modelo mental da organização da informação na fala e (que) corresponde a um padrão prosódico". 
As unidades do padrão informacional se distinguem em três tipologias, como visto em Raso (2012): "as unidades que compõem o texto do enunciado; as unidades que não compõem o texto do enunciado, mas que se dirigem a ele, ou seja, fornecem instruções sobre como interpretar o enunciado ou parte dele; as unidades que não compõem o texto do enunciado e que são dirigidas ao interlocutor". As unidades pertencentes aos dois primeiros grupos são chamadas de unidades textuais; as pertencentes ao último grupo, de unidades dialógicas. Ao primeiro grupo pertencem as unidades de comentário (COM), de tópico (TOP) e de apêndice (seja apêndice de tópico - APT -, seja apêndice de comentário - APC). Ao segundo grupo pertencem o parentético (PAR) e o introdutor locutivo (INT). Já as unidades dialógicas são o fático (PHA), o incipitário (INP), o conativo (CNT), o alocutivo (ALL), o expressivo (EXP) e o conector discursivo (DCT).

COMENTÁRIO (COM) - É a unidade mais importante; é a única que pode figurar sozinha no enunciado, por ter autonomia prosódica e pragmática; assim, é suficiente para formar um ato de fala. A sua função é a de veicular a força ilocucionária do enunciado.

O comentário sempre apresenta um foco entonacional e sua distribuição é livre. É a unidade mais informativa do enunciado, apresentando sempre um conteúdo ilocucionário novo. Quando se trata de um padrão complexo, o comentário pode aparecer sob a forma de comentários múltiplos ou ligados.

TÓPICO (TOP) - Sua função é a de delimitar, do ponto de vista semântico, o comentário. Corresponde ao campo de aplicação da força ilocucionária do comentário. Ele seleciona o domínio de relevância pragmática do ato ilocucionário e sempre antecede o comentário. É a única unidade, além do comentário, que também tem um foco entonacional, sempre observado.

O tópico permite que a ilocução seja distanciada do contexto situacional extralinguístico e se refira ao conteúdo cognitivo do próprio tópico; ele contextualiza, semanticamente, a ilocução, fazendo com que ela seja direcionada ao âmbito semântico fornecido pelo tópico. Sem o TOP, a força ilocucionária do COM é aplicada no contexto pragmático (linguístico e extralinguístico). O tópico funciona como uma substituição linguística do contexto pragmático, o que permite que o comentário seja removido do seu contexto pragmático.

Em uma interação fortemente ancorada no contexto interacional, há pouca necessidade de usar o tópico; ele ocorre mais frequentemente quando, situacionalmente, o âmbito de aplicação da força ilocucionária não é dado. Assim, é mais comum que o tópico ocorra em textos de tipo monológico, pois em tais situações é preciso estabelecer o âmbito textualmente.

APÊNDICE DE COMENTÁRIO - Segue o comentário e realiza sua integração textual. Não apresenta foco e expressa uma repetição ou é um preenchedor (expressão formulaica praticamente sem informação ou com informação retardada). Seria uma "compilação" do texto.

APÊNDICE DE TÓPICO - Segue o tópico e integra o seu texto através da adição de especificações para o ouvinte. Não apresenta foco. Assim como o apêndice de comentário, seria uma "compilação" do texto.

PARENTÉTICO - Tem uma função metalinguística - traz informação sobre o modo como o interlocutor deve interpretar o conteúdo do enunciado, e apresenta um ponto de vista externo ao do comentário; só não aparece no início do enunciado. Quanto ao léxico, vêm itens modalizadores. 
INTRODUTOR LOCUTIVO - Introduz uma metailocução, como elencos, exemplificações e discurso reportado. Indica uma suspensão pragmática do que vinha sendo dito; o que vem a seguir deve ser interpretado em um plano diferente do restante do enunciado. Vem antes do comentário, introduzindo-o. Também pode introduzir unidades informacionais organizadas em forma de lista, como tópico e parentéticos.

FÁTICO - Controla o canal comunicativo, de modo a conservá-lo aberto e garantir o recebimento do enunciado (é uma unidade dialógica).

INCIPITÁRIO - Serve para regular e assegurar o bom funcionamento da interação (lembremos que também se trata de uma unidade dialógica). Abre e regula o canal de comunicação - é sempre a primeira unidade de um padrão informacional, iniciando o turno dialógico.

CONATIVO - Exorta o interlocutor para se engajar de maneira apropriada na iteração para uma mudança de comportamento, induzindo-o a fazer algo ou deixar de fazê-lo.

ALOCUTIVO - Serve para o falante se dirigir a alguém, assinalando coesão social.

EXPRESSIVO - Como unidade dialógica, representa um suporte emocional ao ato de fala serve para assinalar o compartilhamento de uma afiliação social com o interlocutor, o que indica a busca por uma coesão social.

CONECTOR DISCURSIVO - Marca continuidade do discurso - indica ao interlocutor que o processo de construção do texto está em andamento.

Algumas unidades informacionais podem ser fracionadas em mais unidades tonais. Isso é muito raro nos diálogos informais e fica mais comum em textos monológicos e formais. Raso (2012) apresenta as unidades em que pode se dar tal fato: comentário, tópico e parentético, muito raramente apêndice e introdutor locutivo.

A situação apresentada anteriormente acontece por vários motivos: (a) se a dimensão silábica do conteúdo locutivo da unidade for muito grande e não for possível realizá-lo em uma única unidade tonal por razões fisiológicas; (b) se o falante possuir escassa perícia na fala, como acontece frequentemente com falantes muito jovens ou de diastratia baixa; (c) por razões enfáticas; (d) por alguma forma de hesitação.

Quando a unidade informacional realizar-se em mais unidades tonais, o perfil prosódico próprio de dita unidade será realizado na última unidade tonal; as unidades tonais anteriores apresentarão um perfil neutro, sem nenhum valor funcional. Tais unidades tonais são chamadas unidades de escansão (SCA). Como diz Raso (2012), "elas constituem partes tonais diferentes de uma mesma unidade informacional. De fato, elas são sempre composicionais sintática e semanticamente".

Sobre o foco, este consiste em uma associação entre uma proeminência prosódica e uma proeminência semântico pragmática para a Teoria da Língua em Ato. Isso significa dizer que algumas unidades podem, eventualmente, contar com proeminências prosódicas, mas as mesmas não consistirão em foco para a referida teoria. Cresti (2011, p.71) afirma que o foco, ainda que corresponda a uma noção semântica, não tem como domínio de aplicação todo o enunciado, mas a semântica do domínio do tópico ou do comentário, razão pela qual estas unidades de informação sempre contam com um foco, enquanto as demais nunca o apresentam. 
Cresti (2011, p.72) apresenta, ainda, os mais importantes parâmetros que caracterizam a existência de um foco, ou seja, aqueles que marcam a proeminência prosódica. São eles: um movimento perceptivelmente relevante de $\mathrm{F}_{0}$ e um aumento considerável da duração silábica (acompanhado por um aumento da intensidade).

A Teoria da Língua em Ato foi desenvolvida para a análise da fala espontânea, como pode ser facilmente deduzido pela leitura de Raso (2012): “O objetivo deste capítulo é fornecer uma síntese da teoria e explicar como ela permite uma compreensão melhor da fala espontânea através do estudo de corpora. De fato, a teoria foi elaborada em quase 40 anos de estudo de corpora de fala espontânea”. Ainda assim, optamos por utilizá-la para a análise do nosso corpus de leitura com a finalidade de tentar encontrar possíveis relações entre dados de leitura e a proposta da referida teoria. Segundo essa teoria, as unidades informativas que podem ocorrer em situação de leitura são comentário, tópico, apêndice de comentário, apêndice de tópico, parentético e introdutor locutivo, por se tratar de unidades textuais, que "agem sobre a situação comunicativa ou sobre o interlocutor", e não são unidades dialógicas, que "atuam na regulação da interação" (MITTMAN, 2012, p.58).

\section{Corpus e metodologia}

Os dados foram obtidos a partir da gravação de telejornais regulares na TV nos canais TVN, do Chile, e TVE, da Espanha. A gravação dos telejornais se deu no mês de agosto de 2001, em transmissão via satélite por uma TV a cabo. Os telejornais do Chile foram "Edición Dos de 24 horas" e "Edición Vespertina de 24 horas" e os telejornais da Espanha foram "Canal 24 horas" e "Telediario 2". Os telejornais foram gravados integralmente; posteriormente, foram selecionados os enunciados a serem analisados.

Para a seleção, levou-se em consideração que fossem cobertas as variantes estudadas (estilo de fala, origem geográfica e sexo dos falantes). Foi tomado o cuidado de que não houvesse ruído de fundo nem fala sobreposta, o que prejudicaria a análise.

Nosso corpus está formado por um total de seis enunciados por informante em situação de leitura para cada origem geográfica e para cada sexo $(6 \times 2 \times 2=24)$. Assim, nossa análise se encontra baseada em um total de 24 enunciados, sendo seis para cada relação origem geográfica / sexo. Ao ser transcrito, cada enunciado recebeu um rótulo, em função da origem geográfica do falante - Chile (C) ou Espanha (E) - do seu sexo - homem (H) ou mulher (M) - e do estilo de fala - leitura (L). Além disso, existe uma numeração que possui a finalidade de organizar os enunciados. Assim, ao tratarmos do enunciado EHL3, estamos tratando do $3^{\circ}$ enunciado dito por um espanhol, do sexo masculino, em situação de leitura.

Por se tratar de um corpus obtido de telejornais, seria impossível que obtivéssemos os mesmos enunciados. Só seria viável encontrar uma simetria neste sentido se se analisassem dados de outra natureza. Assim, variam a extensão e o assunto de cada enunciado. Tampouco dispomos de informações detalhadas sobre os informantes.

Sobre a Teoria da Língua em Ato, procuramos identificar as unidades de informação tópico, comentário, apêndice de tópico e apêndice de comentário (as unidades informativas presentes em textos monológicos encontradas em nosso corpus), bem como as marcas de foco do tópico e 
do comentário. Após a identificação, pretendemos coletar sua frequência e suas características, por meio do programa de análise acústica PRAAT, tais como duração, comportamento da $\mathrm{F}_{0} \mathrm{e}$ posição no enunciado.

\section{Análise dos dados: proeminências e unidades informacionais}

Conforme já apresentado, analisamos nossos dados de acordo com a Teoria da Língua em Ato, desenvolvida por Cresti (2000), em princípio, para a análise da fala espontânea. As unidades informacionais são obtidas a partir da segmentação prosódica da fala. O pressuposto dessa teoria é o de que, na fala espontânea, cada unidade identifica uma função informativa específica, apresentando uma unidade tonal. Nosso corpus, porém, não é constituído por dados de fala espontânea, uma vez que se trata de um gênero que supõe a oralização de um texto escrito.

Raso (2012, p.95) sistematiza a segmentação da fala em unidades informacionais segundo a Teoria da Língua em Ato: (a) "o que determina a segmentação e a individualização de um enunciado não é (...) a sua estrutura morfossintática, mas a sua forma prosódica”, já que é ela que indica onde e como se deve segmentar a fala; (b) "a prosódia nos diz qual (é) o segmento da fala (que) pode ser interpretado em autonomia", relembrando que a autonomia prosódica reflete uma autonomia pragmática, e não semântica ou morfossintática; e (c) considerando a informação prosódica, "o que parece na transcrição como a mesma estrutura sintática pode de fato ser analisado em um número diferente de estruturas autônomas"; nesse caso, a análise sintática não pode se estender além das fronteiras da unidade estruturada de maneira autônoma.

Ao dividir os enunciados desta pesquisa em unidades informacionais considerando os pressupostos da Teoria da Língua em Ato, tivemos dificuldades em considerar o limite de ditas unidades, uma vez que contamos com apenas um falante para estabelecê-los. Em algumas unidades, ocorreram mais picos de $\mathrm{F}_{0}$ tão ou mais altos do que o que escolhemos como fronteira, mas pareceu-nos que apenas este último exercia um papel delimitador. Também tivemos dúvidas sobre casos em que havia um nítido aumento de duração, associado ou não a um pico de $\mathrm{F}_{0}$. Como critério, então, para estabelecer os limites de uma unidade informacional, consideramos apenas os movimentos de $\mathrm{F}_{0}$ que julgamos corresponder a movimentos intencionais dos falantes.

\section{O papel dos contornos melódicos na delimitação das unidades informacionais}

A unidade informacional, seja ela constituída por um conjunto de palavras ou mesmo por uma única palavra, apresenta um determinado padrão prosódico. Em nosso corpus, constituído por leitura de telejornais, ou seja, discurso monológico, só se encontrariam seis tipos de unidades informacionais postuladas pela TLA: tópico, apêndice de tópico, comentário, apêndice de comentário, parentético e introdutor locutivo. No entanto, só encontramos exemplos de tópico, apêndice de tópico, comentário e apêndice de comentário. Com exceção do apêndice de tópico, que só ocorre uma vez em nossos dados, podemos afirmar que a frequência e a distribuição das demais unidades informacionais é bastante sistemática, como veremos a seguir.

Uma especificidade do tópico e do comentário, segundo essa teoria, é a de apresentar, sempre, um foco, o que já não se dá nos apêndices. O foco corresponde a um núcleo prosódico, ou seja, à proeminência mais relevante. Assim, além de descrever as unidades informacionais encontradas em nosso corpus, realizamos, ainda, uma análise do foco do tópico e do foco do comentário. 
É importante mencionar que o foco, uma marca de proeminência, é identificado a partir de marcas que não estão claramente definidas, pois não há um consenso sobre o conceito de proeminência. Há autores que consideram a proeminência uma categoria relevante pragmaticamente (como dado e novo); outros a relacionam a fenômenos métricos (calculada como a soma de constituintes "fortes" na árvore métrica: sílaba forte, pé forte, palavra fonológica forte etc.). Para alguns, a proeminência se relaciona a pontos do contorno entonativo (pontos em que se localizam os acentos tonais); por fim, há alguns que associam a proeminência ao fato metalinguístico, relacionado à relação dos constituintes no seu domínio (a cabeça do sintagma ou a construção morfológica em geral). Neste trabalho, consideramos o ponto de vista que leva em consideração o contorno entonativo.

Apresentamos, a seguir, os enunciados completos, transcritos a partir da classificação de acordo com a Teoria da Língua em Ato.

CHL1 - con un delincuente muerto y doce detenidos $/=$ TOP = culminó un operativo antinarcóticos de investigaciones en la capital $/=\mathrm{COM}=$ en la acción la policía incautó cerca de cuatrocientos kilos de marihuana $/=\mathrm{COB}=$ paraguaya $\mathrm{y}$ prensada $/ /=\mathrm{COM}=$

CHL2 - el Ministerio de Transportes y los choferes de la locomoción colectiva /=TOP= concordaron en que las nuevas medidas de seguridad que se pondrán en marcha para evitar asaltos tendrán un alto costo $/=\mathrm{COB}=$ lo que incidirá en el valor del pasaje $/ /=\mathrm{COM}=$

CHL3 - retomamos lo policial para contarles $/=$ TOP = que una mujer fue violada durante el asalto a un departamento en el Sector Oriente de la capital $/ /=\mathrm{COM}=$

CHL4 - científicos estadounidenses e italianos $/=\mathrm{TOP}=$ anunciaron que iniciarán en noviembre el proceso para clonar seres humanos $/=\mathrm{COM}=$ el impactante anuncio $/=\mathrm{TOP}=$ fue hecho ante expertos de todo el mundo reunidos en Washington $/=\mathrm{COB}=$ para analizar los pro y contra de la clonación humana $/ /=\mathrm{COM}=$

CHL5 - seguimos con noticias del mundo $/=\mathrm{COM}=$ crece la preocupación de la comunidad internacional tras el arresto de veinticuatro trabajadores humanitarios en Afganistán $/=\mathrm{COB}=$ acusados de predicar el Cristianismo $/ /=\mathrm{COM}=$

CHL6 - con el objetivo de entregarles a los niños de bajos recursos una Navidad inolvidable /=TOP= Luisa Durán de Lagos invitó a setenta empresarios a que apoyen la celebración navideña $/=\mathrm{COM}=$ del dos mil uno $/=\mathrm{APC}=$

EHL1 - la grave situación que vive Oriente Próximo /=TOP= será debatida este lunes por el Consejo de Seguridad de la $\mathrm{ONU} /=\mathrm{COB}=$ que estudia además el envío de observadores a la zona $/=\mathrm{COM}=$ allí la violencia $/=\mathrm{TOP}=$ no cesa $/=\mathrm{COM}=1$ os palestinos enterraban hoy a las últimas víctimas $/=\mathrm{COB}=$ entre las que se encontraban dos niños $/=\mathrm{COM}=$ de corta edad $/ /=\mathrm{APC}=$

EHL2 - el comandante en jefe de las fuerzas de la OTAN el general estadounidense Joseph Ralston $/=\mathrm{TOP}=$ llega hoy a Macedonia para comprobar sobre el terreno $/=\mathrm{COB}=$ si es conveniente o no $/=\mathrm{COB}=$ el despliegue de tres mil quinientos soldados de la alianza tal y como se prevé $/=\mathrm{COB}=$ en el acuerdo firmado entre eslavos y albaneses $/=\mathrm{COM}=$ todas las condiciones se han cumplido $/=\mathrm{COB}=$ todas menos el alto el fuego $/=\mathrm{COB}=$ exigido a la guerrilla albanesa 


\section{$/ /=\mathrm{COM}=$}

EHL3 - en Colombia /=TOP= la INTERPOL sigue la pista a doscientos terroristas extranjeros que podrían entrenar a los guerrilleros colombianos $/=\mathrm{COM}=$ así lo ha desvelado el Departamento Administrativo de Seguridad de Colombia $/=\mathrm{COM}=$ el ejército colombiano ha asegurado que miembros de ETA se hallan en ese país $/=\mathrm{COB}=$ asesorando a la guerrilla del Ejército de Liberación Nacional $/ /=\mathrm{COM}=$

EHL4 - ya en España la coordinación entre el Gobierno Central y el Ejecutivo Vasco en la lucha contra $\mathrm{ETA} /=\mathrm{TOP}=$ se ha pueso se ha puesto en la práctica esta mañana $/=\mathrm{COB}=$ en la reunión que han mantenido el Secretario de Estado de Seguridad y el Viceconsejero Vasco de Interior $/=\mathrm{COM}=$ a ese encuentro $/=\mathrm{TOP}=$ han asistido responsables de información de las Fuerzas de Seguridad del Estado y de las policías autónomas vasca y catalana $/ /=\mathrm{COM}=$

EHL5 - de nuevo las avalanchas de inmigrantes que llegan en pateras a las costas españolas $/=\mathrm{TOP}=$ son noticia $/=\mathrm{COM}=$ entre el fin de semana $\mathrm{y}$ hoy $/=\mathrm{TOP}=$ son ya casi novecientas las personas detenidas por la Guardia Civil /=COM= la mayor parte en las costas de Cádiz $/ /=\mathrm{APC}=$

EHL6 - una mina /=TOP= sin ninguna garantía de seguridad para sus trabajadores $/=\mathrm{APT}=$ ha vuelto a convertirse en una trampa mortal $/=\mathrm{COM}=$ es lo que ha sucedido en una explotación minera $/=\mathrm{COB}=$ en el este de Ucrania $/ /=\mathrm{COM}=$

CML 1 - autoridades de salud /=TOP= llamaron a los padres a prestar atención a los síntomas de la meningitis $/=\mathrm{COM}=$ el cambio de clima y las agradables temperaturas $/=\mathrm{TOP}=$ son un factor que podría aumentar los casos de esta enfermedad $/ /=\mathrm{COM}=$

CML 2 - productores lácteos del sur /=TOP= protestaron frente a la planta de Soprole debido a los bajos precios de la leche fijados por la Asociación de Industrias Lácteas /=COM=el presidente de esta entidad $/=\mathrm{TOP}=$ dijo que están dispuestos a un diálogo pero rechazan las manifestaciones $/ /=\mathrm{COM}=$

CML 3 - en el ex Congreso Nacional /=TOP= la concertación proclamó a sus candidatos a las elecciones parlamentarias de diciembre $/=\mathrm{COM}=$ el presidente de la Democracia Cristiana Patricio Aylwin $/=\mathrm{TOP}=$ asignó también la coordinación del conglomerado oficialista $/ /=\mathrm{COM}=$

CML 4 - el Movimiento de Liberación e Integración Homosexual /=TOP= va a elaborar un proyecto de ley que les permita cambiar su nombre $/=\mathrm{COM}=$ por uno de mujer $/ /=\mathrm{COM}=$

CML 5 - apoderados de una escuela básica de la Comuna de La Quintana aquí en Santiago $/=\mathrm{TOP}=$ denunciaron que un alumno fue ultrajado en el interior del establecimiento $/=\mathrm{COM}=$ la víctima de sólo siete años $/=\mathrm{TOP}=$ acusó al portero $/=\mathrm{COB}=$ de haberlo agredido $/=\mathrm{COB}=$ en un baño $/ /=\mathrm{COM}=$

CML 6 - un verdadero terremoto se produjo en la Alianza por Chile $/=\mathrm{COB}=\quad$ luego que las directivas de Erre Ene y la Udi decidieran bajar a tres candidatos a senadores $/=\mathrm{COB}=$ que incluso ya habían comenzado sus campañas $/=\mathrm{COM}=$ uno de ellos es Sebastián Piñera $/=\mathrm{COB}=$ quien retiró su postulación por la Quinta Región Costa $/ /=\mathrm{COM}=$

EML 1 - en Macedonia /=TOP= prosigue la negociación entre eslavos y la minoría albanesa en la ciudad de Orlid sin presencia de la guerrilla $/=\mathrm{COM}=$ el Ministerio de Interior ha mostrado hoy las armas decomisadas durante la operación en la que murieron cinco miembros de la guer- 
rilla albanesa $/=\mathrm{COB}=\mathrm{y}$ otros cinco más fueron detenidos $/ /=\mathrm{COM}=$

EML 2 - y en Colombia /=TOP= decenas de personas han impedido que cooperantes extranjeros desembarcaran en el puerto fluvial de San Paulo $/=\mathrm{COB}=$ en el Río Magdalena $/=\mathrm{COM}=$ éstos querían llevar ayuda humanitaria a los desplazados por el conflicto entre guerrilla y paramilitares $/ /=\mathrm{COM}=$

EML 3 - la comunidad médica y científica sospecha que las emisiones electromagnéticas de los teléfonos móviles pueden tener consecuencias negativas para la salud $/=\mathrm{COM}=$ así es que la Unión Europea $/=\mathrm{TOP}=$ obliga ya a los fabricantes a limitar las radiaciones $/=\mathrm{COM}=$ en pocos meses $/=\mathrm{TOP}=$ habrá normas todavía más duras $/ /=\mathrm{COM}=$

EML 4 - conclave científico en Washington sobre la clonación humana /=COM= dentro de una hora en la Academia Nacional de las Ciencias $/=\mathrm{TOP}=$ partidarios y detractores expondrán sus argumentos $/=\mathrm{COM}=\mathrm{a}$ favor $/=\mathrm{TOP}=\mathrm{el}$ italiano Antinori $/=\mathrm{COB}=$ que asegura estar en disposición de clonar humanos a partir del próximo otoño $/=\mathrm{COM}=$ en contra $/=\mathrm{TOP}=$ los creadores de la oveja Dolly $/=\mathrm{COM}=$ entre otros $/=\mathrm{APC}=$

EML 5 - Brasil llora a su más famoso novelista Jorge Amado $/=\mathrm{COB}=$ muerto anoche en de un ataque cardiaco $/=\mathrm{COM}=$ el autor en lengua portuguesa más conocido fuera de sus fronteras /=TOP $=$ era también el que mejor había retratado el alma brasileña $/ /=\mathrm{COM}=$

EML 6 - en Valencia / = TOP = dos mil internautas están celebrando un maratón en el que pasan el día y la noche $/=\mathrm{COB}=$ navegando por Internet $/ /=\mathrm{APC}=$

O Quadro 1 apresenta o total de cada unidade informativa encontrada nos enunciados e a média de frequência de cada uma.

\begin{tabular}{l|c|c|c|c|}
\hline & TOP & APT & COM & APC \\
\hline CHL1 & 1 & 0 & 3 & 0 \\
CHL2 & 1 & 0 & 2 & 0 \\
CHL3 & 1 & 0 & 1 & 0 \\
CHL4 & 2 & 0 & 3 & 0 \\
CHL5 & 0 & 0 & 3 & 0 \\
CHL6 & 1 & 0 & 1 & 1 \\
EHL1 & 2 & 0 & 5 & 1 \\
EHL2 & 1 & 0 & 7 & 0 \\
EHL3 & 1 & 0 & 4 & 0 \\
EHL4 & 2 & 0 & 3 & 0 \\
EHL5 & 2 & 0 & 3 & 1 \\
EHL6 & 1 & 1 & 3 & 0 \\
CML1 & 2 & 0 & 2 & 0 \\
CML2 & 2 & 0 & 2 & 0 \\
CML3 & 2 & 0 & 2 & 0 \\
CML4 & 1 & 0 & 1 & 0 \\
CML5 & 2 & 0 & 4 & 0 \\
CML6 & 0 & 0 & 5 & 0 \\
& & & &
\end{tabular}




\begin{tabular}{|c|c|c|c|c|}
\hline EML1 & 1 & 0 & 3 & 0 \\
\hline EML2 & 1 & 0 & 3 & 0 \\
\hline EML3 & 2 & 0 & 3 & 0 \\
\hline EML4 & 3 & 0 & 5 & 1 \\
\hline EML5 & 1 & 0 & 3 & 0 \\
\hline EML6 & 1 & 0 & 2 & 1 \\
\hline TOTAL & 33 & 1 & 73 & 5 \\
\hline $\begin{array}{l}\text { VALOR MÉDIO } \\
\text { DA UNIDADE } \\
\text { POR ENUNCIADO }\end{array}$ & 1,38 & 0,04 & 3,04 & 0,21 \\
\hline
\end{tabular}

Como se identifica facilmente no Quadro 1, a unidade informativa do comentário é a mais frequente. Isso se deve ao fato de ela veicular a força ilocucionária do enunciado, sendo, portanto, a única unidade obrigatória. Apesar de não ser obrigatório, o total de tópicos corresponde quase à metade do total de comentários, por se tratar de enunciados monológicos: o tópico delimita semanticamente o comentário e é muito comum nesse tipo de texto, já que se faz necessário estabelecer textualmente o âmbito de aplicação do comentário. Os apêndices quase não ocorrem em nossos dados: são apenas 4 apêndices de comentário e 1 apêndice de tópico em todo o corpus. Mesmo com poucos dados, podemos comprovar que o comentário, na leitura de notícias, é uma unidade mais complexa do que o tópico, por receber mais apêndices.

\section{Análise dos dados de tópico}

Como dizíamos no final do item anterior, o tópico não é um elemento obrigatório, mas sua presença se torna mais efetiva em textos como os que analisamos, pois são textos monológicos. Assim, torna-se bastante comum encontrar tópicos que estejam estabelecendo, no próprio texto, o âmbito de aplicação do comentário; por exemplo, um domínio espacial ou temporal. O percentual de unidades de tópico, em nosso corpus, é pouco inferior à metade do percentual de unidades de comentário.

No total, contamos com 33 unidades de tópico, sendo que há praticamente a mesma quantidade em todos os apresentadores: 6 no apresentador chileno, 9 na apresentadora chilena, 9 no apresentador espanhol e 9 na apresentadora espanhola. A média de tópicos por enunciado é de 1,38. Em 12 das 24 notícias, encontramos 1 tópico. Há nove notícias com 2 tópicos, uma com 3 e duas sem nenhum dado de tópico.

Em nossos dados, o tópico, com maior frequência, inicia o enunciado ( 19 das 24 notícias). A referida unidade pode ser acompanhada por uma ou mais unidades de comentário. No total, são 19 sequências em que o tópico é acompanhado por um comentário, 8 por dois comentários, 1 por três comentários e 1 por 4 comentários. Há ainda 1 caso em que se observa um apêndice de tópico entre o tópico e o comentário e 3 casos em que um apêndice de comentário segue a sequência tópico-comentário.

Quanto à duração, observamos grande variedade; no entanto, a quantidade de sílabas de cada unidade justifica tal variedade. A média geral de velocidade de fala é de 7,6 S/S. Quanto ao 
sexo, porém, encontramos uma diferença: ainda que por pouco, a velocidade de fala é menor nas mulheres do que nos homens, com menos sílabas por segundo (7,0 S/S na apresentadora chilena - desvio padrão 0,860 -, 7,7 S/S na apresentadora espanhola - desvio padrão 1,090 -, 7,9 S/S no apresentador chileno - desvio padrão 0,237 - e 7,8 S/S no apresentador espanhol - desvio padrão 1,086).

Quanto aos correlatos morfossintáticos da unidade de tópico, encontramos uma grande predominância de tópicos nominais (97\%), com apenas um tópico verbal (3\%). Os tópicos nominais (32 no total - 97\%) tendem a apresentar mais sintagmas nominais (18 no total - 56\%), sendo seguidos pelos sintagmas preposicionais (12 no total - 38\%) e com algumas ocorrências de sintagmas adverbiais ( 2 no total $-6 \%)$. O núcleo dos sintagmas tende a ser um substantivo (91\%), eventualmente uma preposição (6\%) ou um advérbio (3\%). No único tópico verbal observado ( $3 \%$ do total), o verbo se encontra em uma forma finita, sendo uma oração principal.

O foco, como já mencionado algumas vezes neste trabalho, é um elemento de presença obrigatória no tópico. Ele consiste, para a Teoria da Língua em Ato e para o nosso trabalho, em uma associação entre uma proeminência prosódica e outra semântico pragmática. O foco entonacional do tópico ocorre à direita e faz parte da sua forma entonacional, conceito desenvolvido por Firenzuoli e Signorini (2003, apud Mittman, 2012: 152), que corresponde ao conjunto de propriedades prosódicas observadas sistematicamente em determinada unidade informacional e correlacionadas com a função informacional da unidade. Interessam-nos, neste trabalho, a curva melódica, a duração silábica média, os valores máximos e mínimos da frequência fundamental e no ataque da unidade.

Antes de descrever nossos dados, porém, faz-se necessário comentar que, para o italiano, "única [língua] estudada em profundidade até o momento" com base na TLA (MITTMAN, 2012, p.156), foram identificados três perfis melódicos para a unidade de tópico, como pode ser observado no quadro 2 .

\begin{tabular}{|c|c|c|c|}
\hline & Forma do tipo 1 & Forma do tipo 2 & Forma do tipo 3 \\
\hline Frequência & $55 \%$ & $24 \%$ & $21 \%$ \\
\hline $\begin{array}{l}\text { Perfil melódico } \\
\text { no núcleo }\end{array}$ & $\begin{array}{l}\text { movimento ascendente- } \\
\text { descendente }\end{array}$ & $\begin{array}{l}\text { movimento nivelado- } \\
\text { ascendente }\end{array}$ & $\begin{array}{l}\text { movimento descendente- } \\
\text { nivelado-ascendente }\end{array}$ \\
\hline $\begin{array}{l}\text { Duração silábica } \\
\text { média }\end{array}$ & $\begin{array}{c}\text { 0,222 s (alongamento da } \\
\text { última sílaba) }\end{array}$ & $\begin{array}{c}\text { 0,201 s (alongamento da } \\
\text { última sílaba) }\end{array}$ & $\begin{array}{c}\text { 0,302 s (alongamento da } \\
\text { última sílaba) }\end{array}$ \\
\hline $\begin{array}{c}\text { Valor máximo } \\
\text { da } F\end{array}$ & $177 \mathrm{~Hz}(\mathrm{H})$ e $308 \mathrm{~Hz}(\mathrm{M})$ & $225 \mathrm{~Hz}(\mathrm{H})$ e $320 \mathrm{~Hz}(\mathrm{M})$ & $206 \mathrm{~Hz}(\mathrm{H})$ e $318 \mathrm{~Hz}(\mathrm{M})$ \\
\hline $\begin{array}{l}\text { Valor mínimo } \\
\text { da } \mathbf{F}_{0}\end{array}$ & $107 \mathrm{~Hz}(\mathrm{H})$ e $180 \mathrm{~Hz}(\mathrm{M})$ & $135 \mathrm{~Hz}(\mathrm{H})$ e $176 \mathrm{~Hz}(\mathrm{M})$ & $84 \mathrm{~Hz}(\mathrm{H})$ e $167 \mathrm{~Hz}(\mathrm{M})$ \\
\hline $\begin{array}{c}\text { Valor da } F_{0} \text { no } \\
\text { ataque }\end{array}$ & $122 \mathrm{~Hz}(\mathrm{H})$ e $201 \mathrm{~Hz}(\mathrm{M})$ & $139 \mathrm{~Hz}(\mathrm{H})$ e $189 \mathrm{~Hz}(\mathrm{M})$ & $161 \mathrm{~Hz}(\mathrm{H})$ e $209 \mathrm{~Hz}(\mathrm{M})$ \\
\hline $\begin{array}{c}\text { Outras } \\
\text { características }\end{array}$ & $\begin{array}{l}\text { em palavras oxítonas, há } \\
\text { alongamento maior que } \\
\text { permite a realização do } \\
\text { movimento descendente }\end{array}$ & $\begin{array}{c}\text { o movimento ascendente } \\
\text { corresponde à última sílaba } \\
\text { tônica do núcleo e pós- } \\
\text { tônicas }\end{array}$ & $\begin{array}{c}\text { o movimento ascendente } \\
\text { corresponde à última sílaba } \\
\text { do núcleo, seja tônica ou pós- } \\
\text { tônica }\end{array}$ \\
\hline
\end{tabular}

Quadro 2. Características dos perfis melódicos do tópico em italiano (MITTMAN, 2012, p.153,154)

$\mathrm{Na}$ análise do tópico no português, foi encontrado um quarto perfil melódico (MITTMAN, 2012, p.207), que apresenta dois semi núcleos, com uma $\mathrm{F}_{0}$ extra alta na primeira tônica e baixa na última e com alongamento na última tônica, além de intensidade alta nas sílabas nucleares. Para identificar se os tópicos que encontramos em nossos dados de leitura de telejornais correspondem aos perfis já encontrados, passamos a analisar os 33 tópicos. 
Nossos dados apresentam grande coincidência com os da língua italiana ao se aplicar a Teoria da Língua em Ato para a identificação do perfil melódico do núcleo: são os mesmos perfis, também com preferência pelo perfil do tipo 1, ascendente-descendente (22 dados - 67\%); o perfil do tipo 2, nivelado-ascendente, se dá em 6 dados (18\%) e o do tipo 3, descendente-nivelado-ascendente, em 5 dados (15\%). É curioso notar que o perfil do tipo 2 só se dá na Espanha, no homem e na mulher; já o perfil do tipo 3 só se dá no homem espanhol e na mulher chilena. As Figuras 45, 46 e 47 ilustram os 3 perfis encontrados em nossos dados.

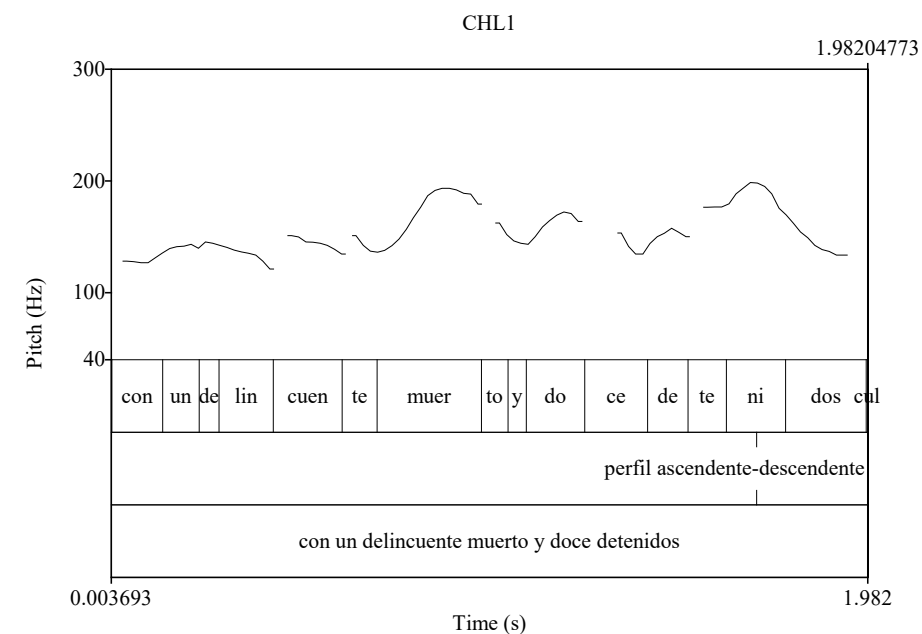

Figura 1. Exemplo do perfil melódico 1 (ascendente-descendente) na unidade informacional "tópico"

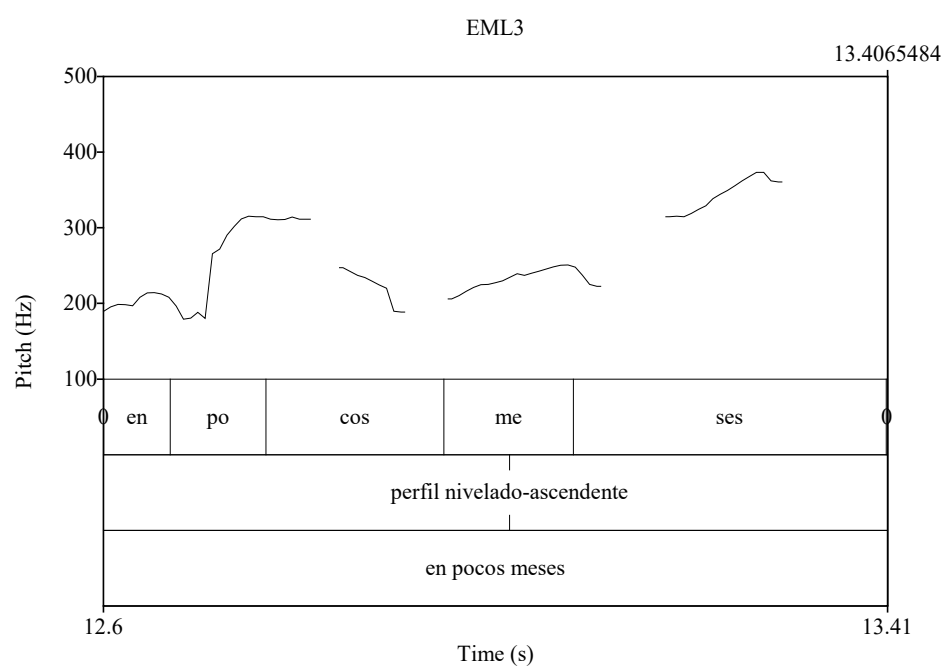

Figura 2. Exemplo do perfil melódico 2 (nivelado-ascendente) na unidade informacional "tópico" 


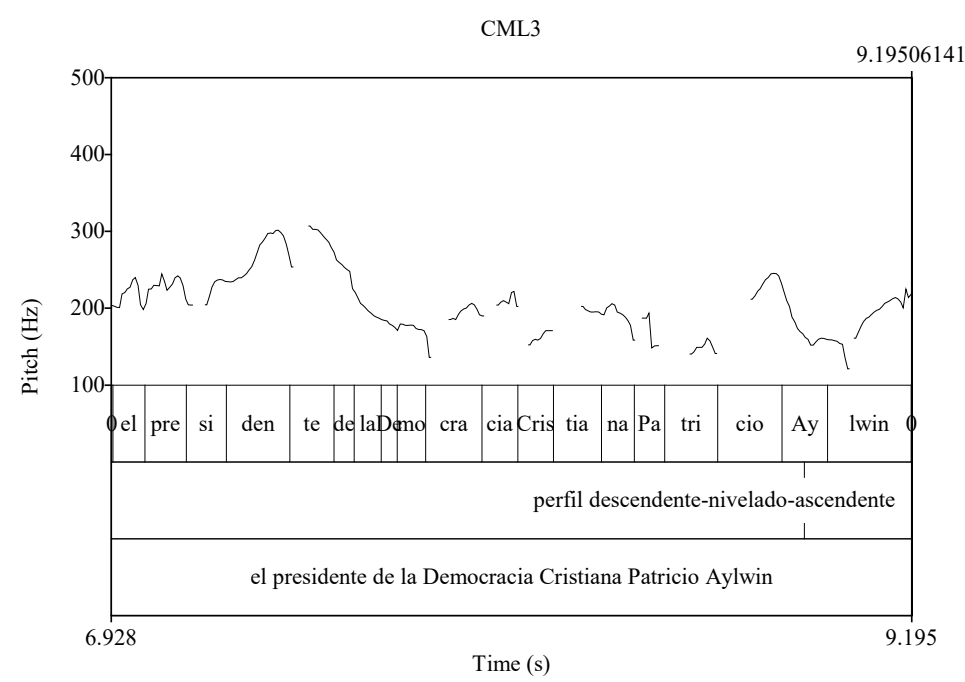

Figura 3. Exemplo do perfil melódico 3 (descendente-nivelado-ascendente) na unidade informacional "tópico"

Após comparar o perfil melódico propriamente dito, passaremos aos demais elementos considerados pela Teoria da Língua em Ato, comparando, então, os resultados obtidos na análise da língua italiana e em nosso corpus.

Sobre a duração silábica média, em nossos dados, verifica-se mais velocidade, em qualquer tipo de perfil melódico, do que na língua italiana. Sobre a $\mathrm{F}_{0}$ máxima, ela tende a ser maior nos nossos dados, com exceção apenas do homem espanhol no perfil 2 (o valor é o mesmo para a mulher chilena no perfil 3), bem como a $\mathrm{F}_{0}$ no ataque, com exceção apenas do homem espanhol no perfil 3. Ao considerarmos a $\mathrm{F}_{0}$ mínima, nossos dados também apresentam valores mais altos em alguns casos, mas em menor escala: observamos o contrário na mulher chilena no perfil de tipo 1, no homem espanhol no perfil de tipo 2 e na mulher chilena no perfil de tipo 3. É importante ressaltar que não conhecemos os valores médios dos dados italianos.

Ao considerar especificamente nossos dados, percebemos, no perfil melódico de tipo 1, que os valores de $\mathrm{F}_{0}$ tendem a ser mais altos na Espanha, com exceção apenas no valor máximo masculino. No perfil melódico de tipo 2, só contamos com dados espanhóis; os valores são mais baixos do que os do perfil de tipo 1, com exceção do valor máximo de $\mathrm{F}_{0}$ nos dados femininos. Quanto ao perfil melódico de tipo 3, só contamos com dados da mulher chilena e do homem espanhol; os valores também são mais baixos do que os do perfil de tipo 1 , menos no valor máximo de $\mathrm{F}_{0}$ feminino e no valor do ataque de $\mathrm{F}_{0}$ masculino.

\section{Análise dos dados de apêndice de tópico}

O apêndice de tópico é uma unidade informativa muito rara em nossos dados de leitura de telejornal: contamos com uma única ocorrência em 24 enunciados.

A função do apêndice de tópico é adicionar uma especificação para o ouvinte; no caso, o dado "TÓPICO una mina APÊNDICE DE TÓPICO sin ninguna garantía de seguridad para sus trabajadores" apresenta a situação em que se encontra a mina referida no tópico. Quanto à velocidade de fala, o valor é maior do que a média de qualquer unidade de tópico. Nosso exemplo de apêndice de tópico segue o tópico que ocorre em posição inicial no enunciado. Observamos que apresenta um nível relativamente mais baixo de $\mathrm{F}_{0}$ do que as demais unidades, por não apresentar foco. 


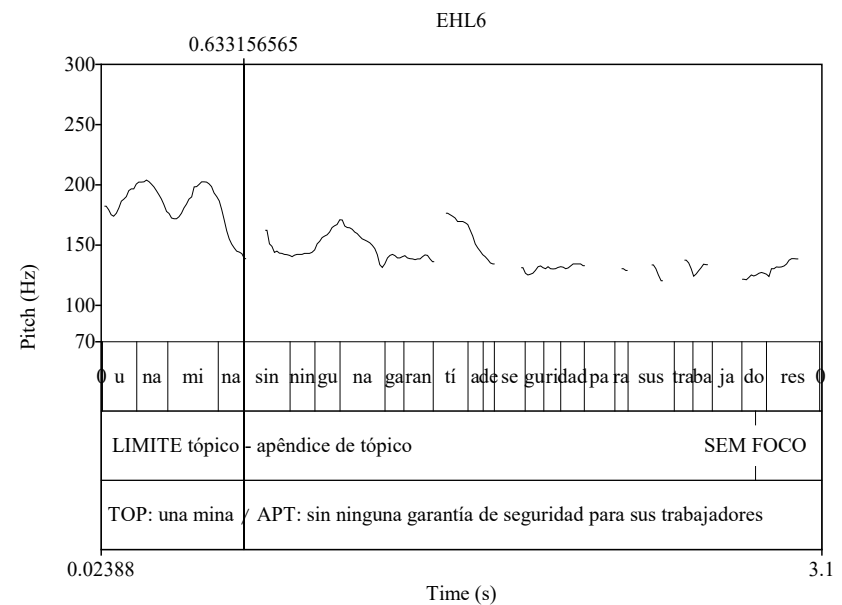

Figura 4. Exemplo da modulação da $\mathrm{F}_{0}$ na unidade informativa "apêndice de tópico"

Como exemplificado na Figura 4, o apêndice de tópico apresenta um valor de $\mathrm{F}_{0}$ mais baixo do que o observado no restante do enunciado: sua $\mathrm{F}_{0}$ máxima é de $177 \mathrm{~Hz}$, ao passo que, no enunciado completo, chega ao valor de $213 \mathrm{~Hz}$.

\section{Análise dos dados de comentário}

O comentário é a unidade informativa mais frequente: ele veicula a força ilocucionária e é a única unidade obrigatória. São de 73 exemplos, com média de 3,04 unidades por enunciado. Porém, identificamos uma diferença regional: observam-se mais unidades do comentário nos enunciados espanhóis; são 43, sendo 24 na leitura do apresentador e 19 na da apresentadora. Nos enunciados chilenos, encontramos um total de 30 exemplos, sendo 13 para o apresentador e 17 para a apresentadora.

A ocorrência mais comum de um comentário (ou de uma sequência deles - comentários ligados) é imediatamente após uma unidade de tópico, com um total de 33 exemplos; são 15 comentários ou sequências de comentários sem um tópico precedente. Do total de 48 grupos com quebra prosódica, há 28 exemplos com 1 comentário, 16 com 2 comentários, 3 com 3 comentários e 1 com 4 comentários. Por fim, das 24 notícias, 5 delas apresentam um comentário inicial, sem um tópico precedente.

Quanto à duração, há uma grande diversidade de valores; porém, tal fato, sem dúvida, se relaciona à quantidade de sílabas de cada unidade. A média geral de velocidade de fala é de 7,3 S/S. No entanto, constatamos uma diferença relacionada ao sexo: a velocidade de fala é maior nos homens do que nas mulheres, com mais sílabas por segundo $(7,9 \mathrm{~S} / \mathrm{S}$ no apresentador chileno - desvio padrão 0,488 -, 7,8 S/S no apresentador espanhol - desvio padrão 1,006 - , 6,6 S/S na apresentadora chilena - desvio padrão 0,700 - e 6,9 S/S na apresentadora espanhola - desvio padrão 1,145).

Quanto aos correlatos morfossintáticos da unidade de comentário, encontramos uma grande predominância de verbos (85\%), prevalecendo as formas finitas (89\% dos verbos) sobre as infinitas ( $11 \%$ do total, sendo 2 casos de infinitivo, 2 de gerúndio e 3 de particípio). Os outros 15\% correspondem a 6 sintagmas nominais e a 5 sintagmas preposicionais, que têm como núcleo 6 substantivos (55\%), 1 adjetivo, 1 verbo em forma finita e 1 em forma infinita (no infinitivo), 1 numeral e 1 pronome. 
Uma característica do comentário é a presença obrigatória de um foco. Assim como nos dados de tópico, o foco no comentário também aparece à direita. Não encontramos, na bibliografia referente à TLA, um tratamento dos dados de comentário como o que encontramos para os dados de tópico, tratamento no qual nos baseamos para desenvolver nossa análise. Assim, optamos por apresentar, no Quadro 3, as características da forma entonacional do comentário (seguimos o conceito de forma entonacional desenvolvido por Firenzuoli e Signorini [2003, apud MITTMAN, 2012, p.152]), ou seja, um modelo utilizado para o tópico. Como o comentário apresenta diversos perfis, decidimos substituir esse item por "modulação da $\mathrm{F}_{0}$ no núcleo".

\begin{tabular}{|c|c|c|c|c|c|c|}
\hline & $\begin{array}{l}\text { Modulação da } \\
\text { E no núcleo }\end{array}$ & $\begin{array}{c}\text { Duração } \\
\text { silábica média }\end{array}$ & $\begin{array}{c}\text { Valor máximo } \\
\text { def }\end{array}$ & $\begin{array}{c}\text { Valor mínimo } \\
\text { de F }\end{array}$ & $\begin{array}{c}\text { Valor médio } \\
\text { de E }\end{array}$ & $\begin{array}{c}\text { Valor da } F_{0} \text { no } \\
\text { ataque }\end{array}$ \\
\hline CHL1 (1) & sobe & $120 \mathrm{~ms}$ & $228 \mathrm{~Hz}$ & $103 \mathrm{~Hz}$ & $152 \mathrm{~Hz}$ & $144 \mathrm{~Hz}$ \\
\hline CHL1(2) & $\begin{array}{l}\text { descendente } \\
\text { ascendente } \\
\text { descendente }\end{array}$ & $119 \mathrm{~ms}$ & $257 \mathrm{~Hz}$ & $101 \mathrm{~Hz}$ & $170 \mathrm{~Hz}$ & $103 \mathrm{~Hz}$ \\
\hline CHL1 (3) & baixa & $139 \mathrm{~ms}$ & $235 \mathrm{~Hz}$ & $89 \mathrm{~Hz}$ & $160 \mathrm{~Hz}$ & $149 \mathrm{~Hz}$ \\
\hline CHL2 (1) & $\begin{array}{l}\text { ascendente } \\
\text { descendente }\end{array}$ & $138 \mathrm{~ms}$ & $242 \mathrm{~Hz}$ & $59 \mathrm{~Hz}$ & $162 \mathrm{~Hz}$ & $173 \mathrm{~Hz}$ \\
\hline CHL2 (2) & surda & $120 \mathrm{~ms}$ & $181 \mathrm{~Hz}$ & $60 \mathrm{~Hz}$ & $130 \mathrm{~Hz}$ & $124 \mathrm{~Hz}$ \\
\hline CHL3 & baixa & $119 \mathrm{~ms}$ & $225 \mathrm{~Hz}$ & $84 \mathrm{~Hz}$ & $165 \mathrm{~Hz}$ & $163 \mathrm{~Hz}$ \\
\hline CHL4 (1) & ascendente & $133 \mathrm{~ms}$ & $251 \mathrm{~Hz}$ & $104 \mathrm{~Hz}$ & $170 \mathrm{~Hz}$ & $158 \mathrm{~Hz}$ \\
\hline CHL4 (2) & ascendente & $135 \mathrm{~ms}$ & $238 \mathrm{~Hz}$ & $117 \mathrm{~Hz}$ & $162 \mathrm{~Hz}$ & $159 \mathrm{~Hz}$ \\
\hline CHL4 (3) & surda & $123 \mathrm{~ms}$ & $248 \mathrm{~Hz}$ & $104 \mathrm{~Hz}$ & $158 \mathrm{~Hz}$ & $152 \mathrm{~Hz}$ \\
\hline CHL5 (1) & $\begin{array}{l}\text { ascendente } \\
\text { descendente }\end{array}$ & $118 \mathrm{~ms}$ & $253 \mathrm{~Hz}$ & $133 \mathrm{~Hz}$ & $168 \mathrm{~Hz}$ & $152 \mathrm{~Hz}$ \\
\hline CHL5 (2) & $\begin{array}{c}\text { sobe } \\
\text { descendente }\end{array}$ & $127 \mathrm{~ms}$ & $273 \mathrm{~Hz}$ & $100 \mathrm{~Hz}$ & $161 \mathrm{~Hz}$ & $190 \mathrm{~Hz}$ \\
\hline CHL5 (3) & baixa & $134 \mathrm{~ms}$ & $223 \mathrm{~Hz}$ & $57 \mathrm{~Hz}$ & $149 \mathrm{~Hz}$ & $129 \mathrm{~Hz}$ \\
\hline CHL6 & ascendente & $127 \mathrm{~ms}$ & $292 \mathrm{~Hz}$ & $116 \mathrm{~Hz}$ & $161 \mathrm{~Hz}$ & $145 \mathrm{~Hz}$ \\
\hline EHL1 (1) & ascendente & $115 \mathrm{~ms}$ & $199 \mathrm{~Hz}$ & $110 \mathrm{~Hz}$ & $135 \mathrm{~Hz}$ & surda \\
\hline EHL1 (2) & sobe & $115 \mathrm{~ms}$ & $256 \mathrm{~Hz}$ & $114 \mathrm{~Hz}$ & $162 \mathrm{~Hz}$ & $136 \mathrm{~Hz}$ \\
\hline EHL1 (3) & $\begin{array}{l}\text { descendente } \\
\text { sobe }\end{array}$ & $187 \mathrm{~ms}$ & $204 \mathrm{~Hz}$ & $119 \mathrm{~Hz}$ & $155 \mathrm{~Hz}$ & $148 \mathrm{~Hz}$ \\
\hline EHL1 (4) & $\begin{array}{l}\text { descendente } \\
\text { sobe }\end{array}$ & $124 \mathrm{~ms}$ & $240 \mathrm{~Hz}$ & $128 \mathrm{~Hz}$ & $170 \mathrm{~Hz}$ & surda \\
\hline EHL1 (5) & ascendente & $161 \mathrm{~ms}$ & $192 \mathrm{~Hz}$ & $131 \mathrm{~Hz}$ & $149 \mathrm{~Hz}$ & $135 \mathrm{~Hz}$ \\
\hline EHL2 (1) & ascendente & $135 \mathrm{~ms}$ & $215 \mathrm{~Hz}$ & $126 \mathrm{~Hz}$ & $171 \mathrm{~Hz}$ & $144 \mathrm{~Hz}$ \\
\hline EHL2 (2) & ascendente & $124 \mathrm{~ms}$ & $178 \mathrm{~Hz}$ & $137 \mathrm{~Hz}$ & $157 \mathrm{~Hz}$ & $155 \mathrm{~Hz}$ \\
\hline EHL2 (3) & ascendente & $142 \mathrm{~ms}$ & $168 \mathrm{~Hz}$ & $62 \mathrm{~Hz}$ & $137 \mathrm{~Hz}$ & $123 \mathrm{~Hz}$ \\
\hline EHL2 (4) & $\begin{array}{l}\text { ascendente } \\
\text { descendente }\end{array}$ & $106 \mathrm{~ms}$ & $204 \mathrm{~Hz}$ & $115 \mathrm{~Hz}$ & $130 \mathrm{~Hz}$ & $128 \mathrm{~Hz}$ \\
\hline EHL2 (5) & ascendente & $118 \mathrm{~ms}$ & $232 \mathrm{~Hz}$ & $119 \mathrm{~Hz}$ & $159 \mathrm{~Hz}$ & $189 \mathrm{~Hz}$ \\
\hline EHL2 (6) & descendente & $129 \mathrm{~ms}$ & $228 \mathrm{~Hz}$ & $129 \mathrm{~Hz}$ & $185 \mathrm{~Hz}$ & $184 \mathrm{~Hz}$ \\
\hline EHL2 (7) & surda & $128 \mathrm{~ms}$ & $189 \mathrm{~Hz}$ & $119 \mathrm{~Hz}$ & $154 \mathrm{~Hz}$ & $128 \mathrm{~Hz}$ \\
\hline EHL3 (1) & ascendente & $139 \mathrm{~ms}$ & $216 \mathrm{~Hz}$ & $113 \mathrm{~Hz}$ & $159 \mathrm{~Hz}$ & $182 \mathrm{~Hz}$ \\
\hline EHL3 (2) & $\begin{array}{l}\text { descendente } \\
\text { ascendente } \\
\text { descendente }\end{array}$ & $117 \mathrm{~ms}$ & $214 \mathrm{~Hz}$ & $113 \mathrm{~Hz}$ & $150 \mathrm{~Hz}$ & surda \\
\hline EHL3 (3) & ascendente & $108 \mathrm{~ms}$ & $212 \mathrm{~Hz}$ & $75 \mathrm{~Hz}$ & $151 \mathrm{~Hz}$ & $138 \mathrm{~Hz}$ \\
\hline EHL3 (4) & surda & $121 \mathrm{~ms}$ & $237 \mathrm{~Hz}$ & $116 \mathrm{~Hz}$ & $166 \mathrm{~Hz}$ & surda \\
\hline EHL4 (1) & ascendente & $116 \mathrm{~ms}$ & $199 \mathrm{~Hz}$ & $72 \mathrm{~Hz}$ & $148 \mathrm{~Hz}$ & $160 \mathrm{~Hz}$ \\
\hline EHL4 (2) & ascendente & $125 \mathrm{~ms}$ & $195 \mathrm{~Hz}$ & $112 \mathrm{~Hz}$ & $144 \mathrm{~Hz}$ & $131 \mathrm{~Hz}$ \\
\hline EHL4 (3) & surda & $136 \mathrm{~ms}$ & $240 \mathrm{~Hz}$ & $117 \mathrm{~Hz}$ & $159 \mathrm{~Hz}$ & $146 \mathrm{~Hz}$ \\
\hline
\end{tabular}




\begin{tabular}{|c|c|c|c|c|c|c|}
\hline EHL5 (1) & $\begin{array}{c}\text { ascendente } \\
\text { descendente }\end{array}$ & $152 \mathrm{~ms}$ & $185 \mathrm{~Hz}$ & $117 \mathrm{~Hz}$ & $139 \mathrm{~Hz}$ & $130 \mathrm{~Hz}$ \\
\hline EHL5 (2) & $\begin{array}{l}\text { ascendente } \\
\text { descendente }\end{array}$ & $158 \mathrm{~ms}$ & $225 \mathrm{~Hz}$ & $121 \mathrm{~Hz}$ & $152 \mathrm{~Hz}$ & $138 \mathrm{~Hz}$ \\
\hline EHL6 (1) & $\begin{array}{c}\text { sobe } \\
\text { descendente }\end{array}$ & $127 \mathrm{~ms}$ & $155 \mathrm{~Hz}$ & $110 \mathrm{~Hz}$ & $130 \mathrm{~Hz}$ & $128 \mathrm{~Hz}$ \\
\hline EHL6 (2) & ascendente & $120 \mathrm{~ms}$ & $214 \mathrm{~Hz}$ & $127 \mathrm{~Hz}$ & $160 \mathrm{~Hz}$ & $141 \mathrm{~Hz}$ \\
\hline EHL6 (3) & surda & $119 \mathrm{~ms}$ & $200 \mathrm{~Hz}$ & $70 \mathrm{~Hz}$ & $137 \mathrm{~Hz}$ & $132 \mathrm{~Hz}$ \\
\hline CML1 (1) & $\begin{array}{c}\text { sobe } \\
\text { descendente }\end{array}$ & $162 \mathrm{~ms}$ & $329 \mathrm{~Hz}$ & $112 \mathrm{~Hz}$ & $192 \mathrm{~Hz}$ & $171 \mathrm{~Hz}$ \\
\hline CML1 (2) & surda & $177 \mathrm{~ms}$ & $351 \mathrm{~Hz}$ & $125 \mathrm{~Hz}$ & $205 \mathrm{~Hz}$ & $280 \mathrm{~Hz}$ \\
\hline CML2 (1) & $\begin{array}{l}\text { ascendente } \\
\text { descendente }\end{array}$ & $164 \mathrm{~ms}$ & $339 \mathrm{~Hz}$ & $112 \mathrm{~Hz}$ & $203 \mathrm{~Hz}$ & $199 \mathrm{~Hz}$ \\
\hline CML2 (2) & baixa & $144 \mathrm{~ms}$ & $356 \mathrm{~Hz}$ & $111 \mathrm{~Hz}$ & $238 \mathrm{~Hz}$ & $336 \mathrm{~Hz}$ \\
\hline CML3 (1) & $\begin{array}{l}\text { ascendente } \\
\text { descendente }\end{array}$ & $163 \mathrm{~ms}$ & $346 \mathrm{~Hz}$ & $101 \mathrm{~Hz}$ & $187 \mathrm{~Hz}$ & $187 \mathrm{~Hz}$ \\
\hline CML3 (2) & surda & $149 \mathrm{~ms}$ & $393 \mathrm{~Hz}$ & $110 \mathrm{~Hz}$ & $175 \mathrm{~Hz}$ & $187 \mathrm{~Hz}$ \\
\hline CML4 (1) & ascendente & $157 \mathrm{~ms}$ & $367 \mathrm{~Hz}$ & $135 \mathrm{~Hz}$ & $230 \mathrm{~Hz}$ & $284 \mathrm{~Hz}$ \\
\hline CML4 (2) & surda & $169 \mathrm{~ms}$ & $276 \mathrm{~Hz}$ & $178 \mathrm{~Hz}$ & $232 \mathrm{~Hz}$ & $208 \mathrm{~Hz}$ \\
\hline CML5 (1) & $\begin{array}{l}\text { ascendente } \\
\text { descendente }\end{array}$ & $160 \mathrm{~ms}$ & $339 \mathrm{~Hz}$ & $105 \mathrm{~Hz}$ & $223 \mathrm{~Hz}$ & $226 \mathrm{~Hz}$ \\
\hline CML5 (2) & ascendente & $154 \mathrm{~ms}$ & $394 \mathrm{~Hz}$ & $151 \mathrm{~Hz}$ & $233 \mathrm{~Hz}$ & $157 \mathrm{~Hz}$ \\
\hline CML5 (3) & ascendente & $121 \mathrm{~ms}$ & $249 \mathrm{~Hz}$ & $124 \mathrm{~Hz}$ & $169 \mathrm{~Hz}$ & $146 \mathrm{~Hz}$ \\
\hline CML5 (4) & baixa & $168 \mathrm{~ms}$ & $280 \mathrm{~Hz}$ & $94 \mathrm{~Hz}$ & $189 \mathrm{~Hz}$ & $147 \mathrm{~Hz}$ \\
\hline CML6 (1) & ascendente & $129 \mathrm{~ms}$ & $366 \mathrm{~Hz}$ & $126 \mathrm{~Hz}$ & $210 \mathrm{~Hz}$ & $253 \mathrm{~Hz}$ \\
\hline CML6 (2) & ascendente & $141 \mathrm{~ms}$ & $393 \mathrm{~Hz}$ & $123 \mathrm{~Hz}$ & $209 \mathrm{~Hz}$ & $217 \mathrm{~Hz}$ \\
\hline CML6 (3) & $\begin{array}{c}\text { sobe } \\
\text { descendente }\end{array}$ & $134 \mathrm{~ms}$ & $387 \mathrm{~Hz}$ & $119 \mathrm{~Hz}$ & $248 \mathrm{~Hz}$ & $285 \mathrm{~Hz}$ \\
\hline CML6 (4) & ascendente & $150 \mathrm{~ms}$ & $350 \mathrm{~Hz}$ & $139 \mathrm{~Hz}$ & $231 \mathrm{~Hz}$ & $232 \mathrm{~Hz}$ \\
\hline CML6 (5) & baixa & $155 \mathrm{~ms}$ & $356 \mathrm{~Hz}$ & $104 \mathrm{~Hz}$ & $198 \mathrm{~Hz}$ & $222 \mathrm{~Hz}$ \\
\hline EML1 (1) & $\begin{array}{l}\text { ascendente } \\
\text { descendente }\end{array}$ & $141 \mathrm{~ms}$ & $320 \mathrm{~Hz}$ & $145 \mathrm{~Hz}$ & $218 \mathrm{~Hz}$ & $251 \mathrm{~Hz}$ \\
\hline EML1 (2) & ascendente & $124 \mathrm{~ms}$ & $346 \mathrm{~Hz}$ & $165 \mathrm{~Hz}$ & $232 \mathrm{~Hz}$ & $237 \mathrm{~Hz}$ \\
\hline EML1 (3) & descendente & $174 \mathrm{~ms}$ & $284 \mathrm{~Hz}$ & $144 \mathrm{~Hz}$ & $218 \mathrm{~Hz}$ & $213 \mathrm{~Hz}$ \\
\hline EML2 (1) & $\begin{array}{c}\text { sobe } \\
\text { descendente }\end{array}$ & $138 \mathrm{~ms}$ & $448 \mathrm{~Hz}$ & $153 \mathrm{~Hz}$ & $223 \mathrm{~Hz}$ & $251 \mathrm{~Hz}$ \\
\hline EML2 (2) & $\begin{array}{l}\text { ascendente } \\
\text { descendente }\end{array}$ & $173 \mathrm{~ms}$ & $238 \mathrm{~Hz}$ & $140 \mathrm{~Hz}$ & $197 \mathrm{~Hz}$ & $170 \mathrm{~Hz}$ \\
\hline EML2 (3) & descendente & $130 \mathrm{~ms}$ & $339 \mathrm{~Hz}$ & $151 \mathrm{~Hz}$ & $231 \mathrm{~Hz}$ & $269 \mathrm{~Hz}$ \\
\hline EML3 (1) & $\begin{array}{c}\text { ascendente } \\
\text { descendente }\end{array}$ & $139 \mathrm{~ms}$ & $340 \mathrm{~Hz}$ & $158 \mathrm{~Hz}$ & $226 \mathrm{~Hz}$ & $239 \mathrm{~Hz}$ \\
\hline EML3 (2) & $\begin{array}{c}\text { sobe } \\
\text { descendente }\end{array}$ & $153 \mathrm{~ms}$ & $329 \mathrm{~Hz}$ & $145 \mathrm{~Hz}$ & $207 \mathrm{~Hz}$ & $239 \mathrm{~Hz}$ \\
\hline EML3 (3) & descendente & $220 \mathrm{~ms}$ & $315 \mathrm{~Hz}$ & $142 \mathrm{~Hz}$ & $236 \mathrm{~Hz}$ & $189 \mathrm{~Hz}$ \\
\hline EML4 (1) & ascendente & $128 \mathrm{~ms}$ & $345 \mathrm{~Hz}$ & $175 \mathrm{~Hz}$ & $247 \mathrm{~Hz}$ & $256 \mathrm{~Hz}$ \\
\hline EML4 (2) & baixa & $197 \mathrm{~ms}$ & $330 \mathrm{~Hz}$ & $142 \mathrm{~Hz}$ & $219 \mathrm{~Hz}$ & $202 \mathrm{~Hz}$ \\
\hline EML4 (3) & $\begin{array}{l}\text { ascendente } \\
\text { descendente }\end{array}$ & $112 \mathrm{~ms}$ & $287 \mathrm{~Hz}$ & $147 \mathrm{~Hz}$ & $215 \mathrm{~Hz}$ & $193 \mathrm{~Hz}$ \\
\hline EML4 (4) & $\begin{array}{c}\text { sobe } \\
\text { descendente }\end{array}$ & $138 \mathrm{~ms}$ & $298 \mathrm{~Hz}$ & $137 \mathrm{~Hz}$ & $224 \mathrm{~Hz}$ & $204 \mathrm{~Hz}$ \\
\hline EML4 (5) & ascendente & $114 \mathrm{~ms}$ & $324 \mathrm{~Hz}$ & $172 \mathrm{~Hz}$ & $239 \mathrm{~Hz}$ & $180 \mathrm{~Hz}$ \\
\hline EML5 (1) & ascendente & $157 \mathrm{~ms}$ & $307 \mathrm{~Hz}$ & $178 \mathrm{~Hz}$ & $232 \mathrm{~Hz}$ & $248 \mathrm{~Hz}$ \\
\hline EML5 (2) & $\begin{array}{l}\text { ascendente } \\
\text { descendente }\end{array}$ & $152 \mathrm{~ms}$ & $324 \mathrm{~Hz}$ & $155 \mathrm{~Hz}$ & $215 \mathrm{~Hz}$ & $261 \mathrm{~Hz}$ \\
\hline EML5 (3) & descendente & $141 \mathrm{~ms}$ & $310 \mathrm{~Hz}$ & $143 \mathrm{~Hz}$ & $220 \mathrm{~Hz}$ & $205 \mathrm{~Hz}$ \\
\hline EML6 (1) & ascendente & $148 \mathrm{~ms}$ & $363 \mathrm{~Hz}$ & $171 \mathrm{~Hz}$ & $253 \mathrm{~Hz}$ & $261 \mathrm{~Hz}$ \\
\hline EML6 (2) & descendente & $151 \mathrm{~ms}$ & $319 \mathrm{~Hz}$ & $144 \mathrm{~Hz}$ & $238 \mathrm{~Hz}$ & $241 \mathrm{~Hz}$ \\
\hline
\end{tabular}

Quadro 3. Características dos perfis melódicos do comentário nos 73 dados analisados em leitura de telejornais 
Ao considerarmos a modulação da $\mathrm{F}_{0}$ no núcleo, percebemos que os 20 comentários que se encontram em posição final de enunciado tendem a apresentar (a) um ensurdecimento (9 dados - 45\%), (b) um movimento baixo constante (6 dados - 30\%) ou (c) um movimento descendente (5 dados - 25\%). É interessante notar que todos os casos de movimento descendente se dão na mulher espanhola; seu único caso de comentário final com outro comportamento se dá em um dado com um apêndice de comentário que segue o comentário. As Figuras 5, 6 e 7 representam tais comportamentos, na mesma sequência.

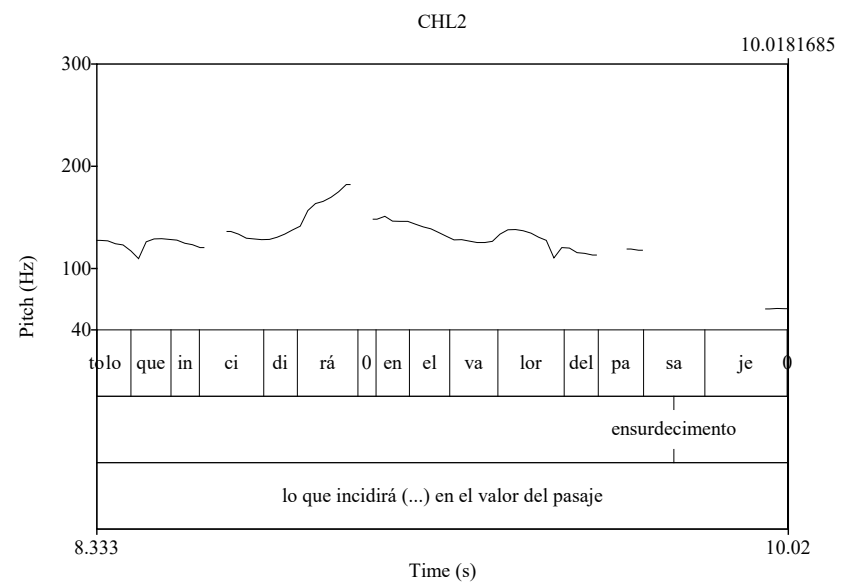

Figura 5. Tipo 1 de modulação da $\mathrm{F}_{0}$ no núcleo do comentário em final de enunciado: ensurdecimento

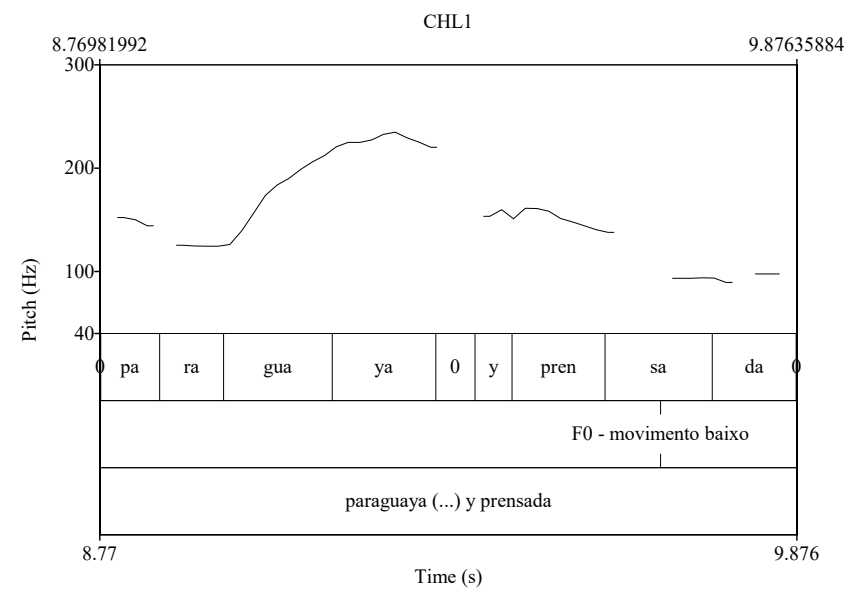

Figura 6. Tipo 2 de modulação da $\mathrm{F}_{0}$ no núcleo do comentário em final de enunciado: movimento baixo constante

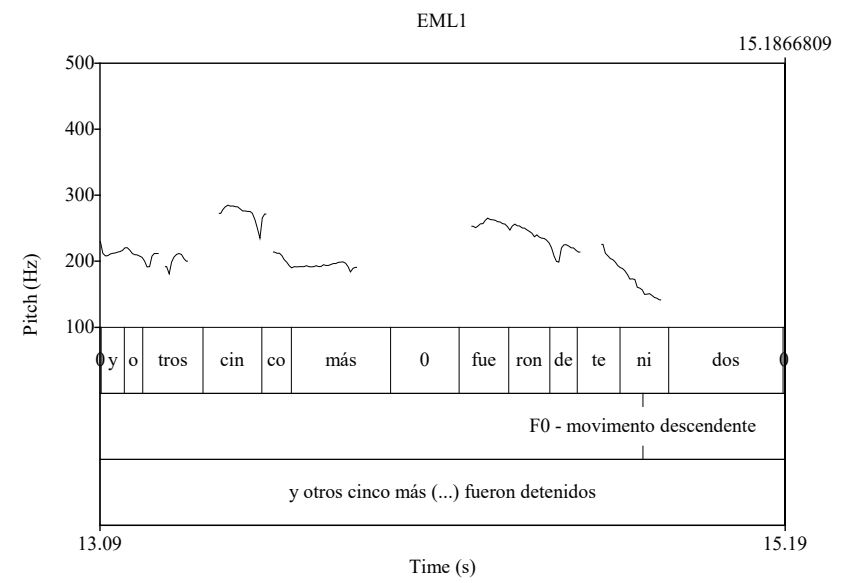

Figura 7. Tipo 3 de modulação da $\mathrm{F}_{0}$ no núcleo do comentário em final de enunciado: movimento descendente 
Sobre os 49 comentários que não se encontram em posição final de enunciado, encontramos duas tendências: a primeira se refere aos comentários que estão numa sequência de comentários ligados e não representam o último elemento da referida sequência; a segunda tendência se refere aos comentários que representam o último elemento da sequência ou aos comentários isolados.

No primeiro caso, são 25 dados. 18 deles (72\%) apresentam um movimento ascendente, 4 (16\%) um movimento ascendente descendente e 3 (12\%) aumentam mas apresentam um movimento descendente. É importante ressaltar que, além dos 49 comentários mencionados no parágrafo anterior, existem outros 4 que são seguidos por um apêndice de comentário; 3 deles seguem a tendência aqui apresentada (movimento ascendente) e 1, o movimento ascendente descendente. A Figura 8 ilustra o movimento predominante desse tipo de comentário, ascendente.

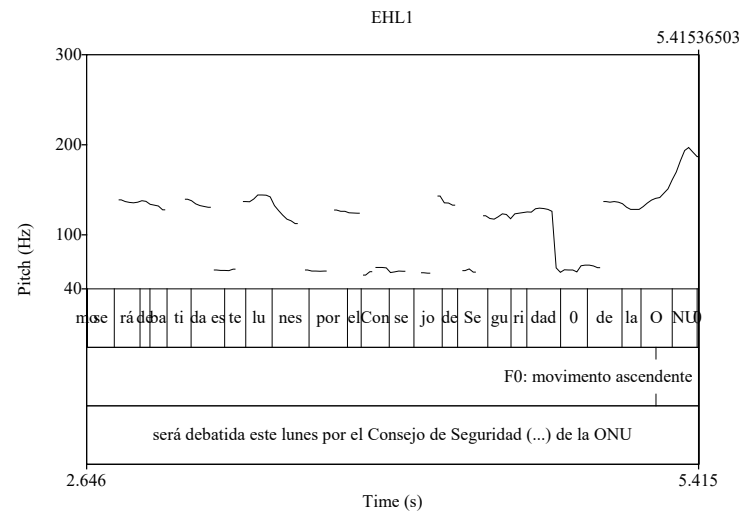

Figura 8. Modulação da $\mathrm{F}_{0}$ predominante no núcleo do comentário em posição não final de uma sequência de comentários ligados: movimento ascendente

No caso de comentários ligados em posição final da sequência ou de comentários isolados, são 24 dados. 14 deles (58\%) apresentam um movimento ascendente descendente, 8 (33\%) aumentam mas apresentam um movimento descendente, 1 (4\%) apresenta um movimento descendente e $1(4 \%)$ apresenta um movimento baixo constante. As Figuras 9 e 10 ilustram os movimentos predominantes deste tipo de comentário, ascendente descendente e aumento com movimento descendente.

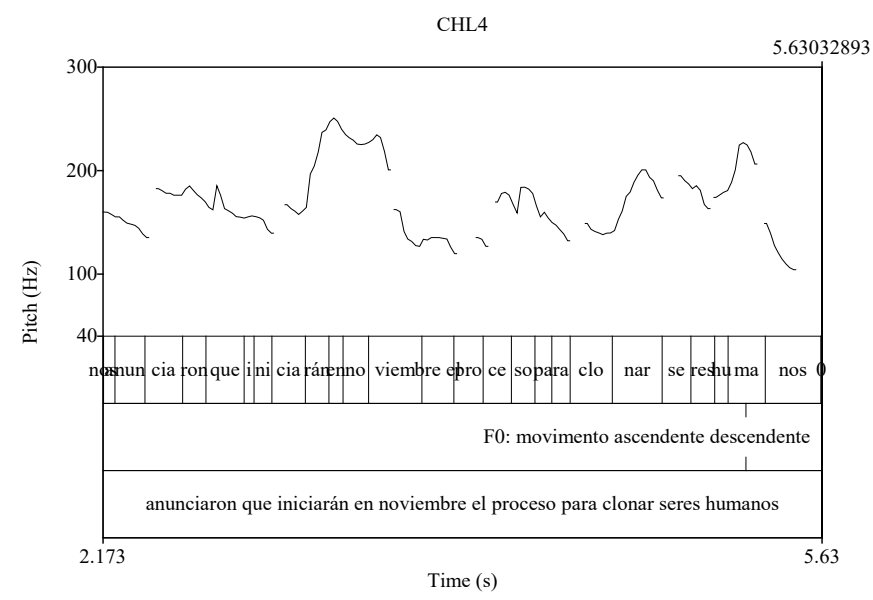

Figura 9. Modulação da $\mathrm{F}_{0}$ predominante no núcleo do comentário em posição final de uma sequência de comentários ligados ou em um comentário isolado: movimento ascendente descendente 


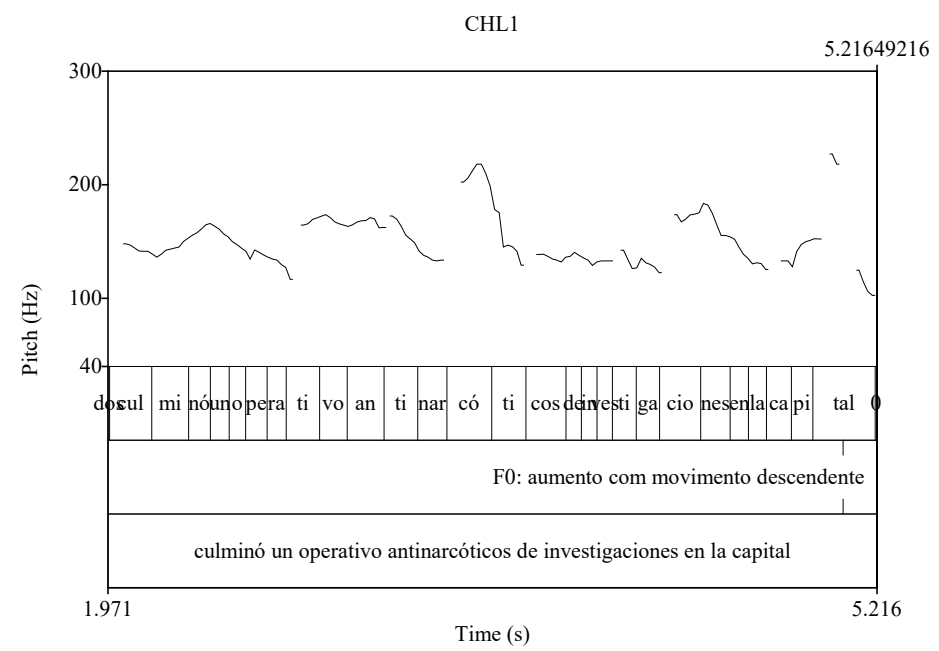

Figura 10. $2^{\circ}$ tipo de modulação da $\mathrm{F}_{0}$ no núcleo do comentário em posição final de uma sequência de comentários ligados ou em um comentário isolado: aumento com movimento descendente

Passamos, agora, a outros elementos. É interessante notar que, de maneira geral, o valor da $\mathrm{F}_{0}$ no ataque se encontra bastante próximo ao valor da $\mathrm{F}_{0}$ média. Percebemos, também, que os apresentadores da Espanha (de ambos os sexos) apresentam uma menor variação de valores de $\mathrm{F}_{0}$, ou seja, sua $\mathrm{F}_{0}$ mínima é maior e sua $\mathrm{F}_{0}$ máxima é menor do que a dos apresentadores do Chile (de ambos os sexos). É de notar, ainda, algo já mencionado anteriormente, relacionado à velocidade de fala: os homens apresentam uma fala mais rápida, emitindo sílabas mais curtas.

\section{Análise dos dados de apêndice de comentário}

O apêndice de comentário, ainda que pouco frequente, se apresenta em maior quantidade do que o apêndice de tópico; são 5 dados. Há um dado para o homem chileno e dois para cada falante espanhol. Todos os 5 apêndices de comentário ocorrem na parte final do enunciado completo, indicando seu fim. A média de velocidade da fala é de 6,3 S/S (desvio padrão 1,156), menor do que nas demais unidades informativas, o que gera uma fala mais lenta, que marca o final da notícia como um todo.

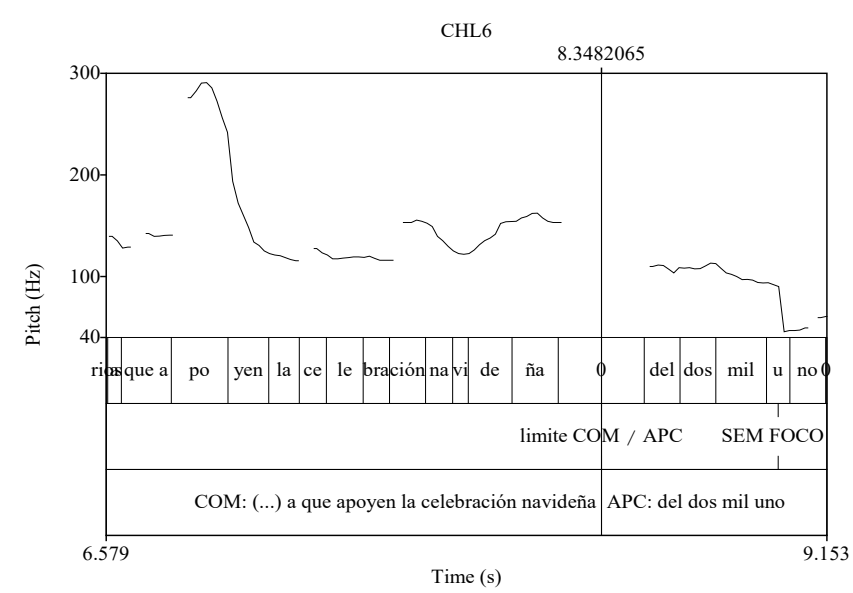

Figura 11. Exemplo da modulação da $\mathrm{F}_{0}$ na unidade informativa "apêndice de comentário"

Como exemplificado na Figura 11, os apêndices de comentário, assim como os apêndices de tópico, tendem a apresentar um valor de $\mathrm{F}_{0}$ mais baixo do que o observado no restante do enunciado. No caso específico de CHL6, a $\mathrm{F}_{0}$ máxima é de $114 \mathrm{~Hz}$, com movimento sempre descen- 
dente, ao passo que, no enunciado completo, chega ao valor de $292 \mathrm{~Hz}$. É importante recordar que, como visto no capítulo precedente, é comum que a $\mathrm{F}_{0}$ caia bastante no final dos enunciados de leitura como um todo.

\section{Conclusão}

Nosso objetivo, neste trabalho, foi o de descrever o fonoestilo telejornal, mais especificamente a leitura profissional da notícia por parte de seus apresentadores, do ponto de vista entonacional, em duas variedades da língua espanhola, a do Chile e a da Espanha. Para tanto, dividimos os 24 enunciados completos em 112 unidades informativas, segundo os pressupostos da Teoria da Língua em Ato. Em tal análise, aceitamos o desafio de aplicar tal teoria sob um novo ponto de vista, uma vez que ela foi desenvolvida para a análise da fala espontânea e, até onde sabemos, ainda não havia sido aplicada a dados monológicos de leitura.

Ao considerarmos as unidades informativas de acordo com a Teoria da Língua em Ato, já sabíamos de antemão que só poderíamos encontrar seis tipos, que são aqueles que compõem o texto do enunciado ou se dirigem a ele. Porém, dos seis tipos de unidades informativas, só encontramos 4: o tópico, o comentário, o apêndice de tópico e o apêndice de comentário.

Sobre os apêndices, encontramos poucos dados: apenas 1 apêndice de tópico e 4 apêndices de comentário. Algo que nos chamou a atenção no apêndice de comentário é o fato de sua posição ser sempre o final do enunciado em nossos dados. Outro elemento caracterizador, já apresentado pela teoria, é a ausência de foco em ambos os elementos, com um padrão de $\mathrm{F}_{0}$ mais baixo do que o resto do enunciado.

A unidade de tópico foi bastante comum em nosso corpus: foram 33 dados, contra 73 do comentário, a unidade mais importante, sendo a única obrigatória. Em geral, as unidades de comentário (na maioria das vezes, uma ou duas) são precedidas por uma unidade de tópico. Esse par não se dá apenas em 15 das 48 sequências, sendo que em 5 vezes o enunciado é iniciado pelo próprio comentário. $\mathrm{O}$ fato de geralmente haver um tópico antecedendo um comentário ou uma sequência deles indica uma proporção de topicalização elevada neste gênero oral (leitura de notícias em telejornais), provavelmente porque, como já previsto pela Teoria da Língua em Ato, a leitura de telejornais é um tipo de texto monológico, em que se faz necessário apresentar textualmente o elemento sobre o qual se aplica a unidade comentário.

Quanto aos correlatos morfossintáticos, predominam, no tópico, unidades nominais (97\%), com um substantivo como núcleo (91\% dos tópicos nominais). Já no comentário, predominam unidades verbais (85\%), com $89 \%$ destas em formas finitas. Ambos os resultados se assemelham aos encontrados na língua italiana.

Uma característica das unidades de tópico e de comentário é apresentar um foco, expresso por um aumento de $\mathrm{F}_{0}$. Encontramos 3 perfis melódicos para o tópico, os mesmos encontrados para a língua italiana - ascendente-descendente, nivelado-ascendente e descendente-nivelado-ascendente. Encontramos movimentos de $\mathrm{F}_{0}$ para o comentário que caracterizam sua posição no enunciado: para os comentários não finais de uma sequência de comentários ligados, um movimento ascendente; para os comentários finais de uma sequência ou para os comentários isolados que não estejam em posição final de enunciado, um movimento descendente; e para os 
comentários em posição final de enunciado, um movimento constante baixo ou um ensurdecimento.

\section{Artigo recebido: 14/10/2015}

\section{Artigo aceito: 19/10/2015}

\section{Referências}

ARANTES, Pablo; LIMA, Maria Luiza Cunha; BARBOSA, Plinio A. "Some prosodic correlates of referential status in Brazilian Portuguese”. Diadorim / Revista de Estudos Linguísticos e Literários do Programa de Pós-Graduação em Letras Vernáculas da Universidade Federal do Rio de Janeiro. Volume 12, Dezembro 2012. Disponível em http://www.revistadiadorim.Letras. ufrj.br. Acesso em: 16 mar. 2013.

CRESTI, Emanuela. The definition of Focus in Language into Acto Theory (L AcT). In: MELLO, Heliana, PANUNZI, Alessandro e RASO, Tommaso (Org.). Pragmatics and Prosody. Illocution, Modality, Attitude, Information Patterning and Speech Annotation. Firenze: Firenze University Press, 2011.

Corpus di italiano parlato. Volume I: Introduzione. Firenze: Accademia della Crusca,

2000.

LAMBRECHT, Knud. Information Structure and Sentence Form. Topic, Focus and the Mental Representation of Discourse Referents. Cambridge: Cambridge University Press, 1994.

MITTMAN, Mariualê Malvessi. O C-ORAL-BRASIL e o estudo da fala informal: um novo olhar sobre o Tópico no Português Brasileiro. Tese (Doutorado em Linguística) - Faculdade de Letras, UFMG, Belo Horizonte, 2012.

RASO, T. O C-Oral-Brasil e a Teoria da Língua em Ato. In: RASO, T. e MELLO, H. (Orgs.) C-Oral-Brasil: Corpus de Referência do Português Brasileiro Falado Informal. Belo Horizonte: UFMG, 2012, pp 91-213. 